\title{
Working
}

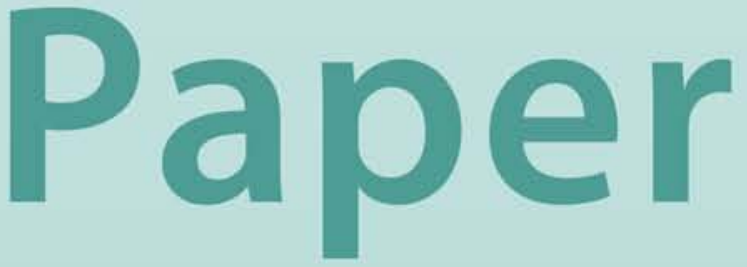


Economic Growth and Poverty Reduction in Sub-Saharan Africa

Gary Moser and Toshihiro Ichida 


\title{
IMF Working Paper
}

African Department

\section{Economic Growth and Poverty Reduction in Sub-Saharan Africa}

\author{
Prepared by Gary Moser and Toshihiro Ichida
}

Authorized for distribution by Ernesto Hernández-Catá

August 2001

\begin{abstract}
The views expressed in this Working Paper are those of the author(s) and do not necessarily represent those of the IMF or IMF policy. Working Papers describe research in progress by the author(s) and are published to elicit comments and to further debate.
\end{abstract}

This study confirms a strong and robust relationship between economic growth and poverty reduction in sub-Saharan Africa. Employing a panel of 46 countries covering the period 1972-97, the analysis finds that a 10 percent increase in per capita GDP leads to a 1 percent increase in life expectancy, a 3-4 percent decline in infant mortality rates, and a $3 \frac{1}{2}-4$ percent increase in the rate of gross primary school enrollment. The results are robust for high- and low-income, as well as fast- and slow-growth, countries. The study also finds that quality of growth, civil conflict, HIV/AIDs, civil and institutional freedom, and island economies are important control variables that help explain the variability of poverty across Africa. A country's latitude is not found to be a significant factor explaining life expectancy or infant mortality rates, though it is a significant factor explaining gross primary school enrollments.

JEL Classification Numbers: I12, I21, I31, O10

Keywords: Poverty, Growth, Human Development, Health, Education, Africa

Author's E-Mail Address: gmoser@imf.org, ti44@columbia.edu

\footnotetext{
${ }^{1} \mathrm{Mr}$. Ichida is currently a doctoral candidate at Columbia University. We would like to thank the participants of the April 2001 IMF Workshop on Macroeconomic Policies and Poverty Reduction and the African Department's informal seminar, as well as Ibrahim Elbadawi, Ernesto Hernández-Catá and Dan Ghura, for very useful comments and suggestions.
} 
Contents

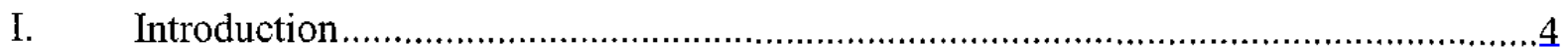

II. The Links Between Growth and Poverty .............................................................

III. Poverty Trends in Sub-Saharan Africa (SSA) ……...........................................

A. Africa's Widening Poverty Gap.............................................................

B. Civil Conflict and Poverty …….................................................................

C. Economic Growth and Poverty ...............................................................11

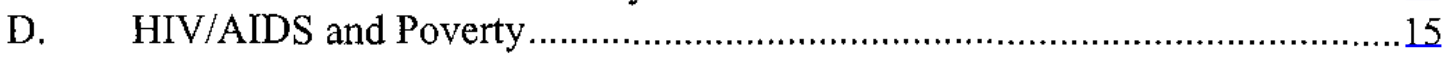

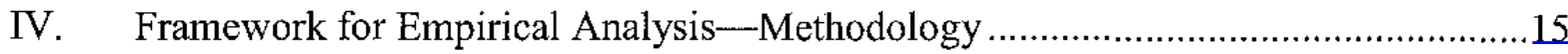

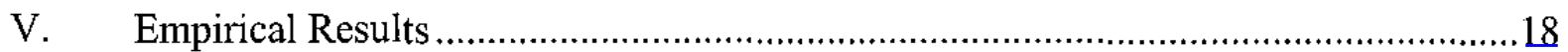

A. Causal Relationship Between Growth and Non-Income Poverty...................18

B. Empirical Results-The Basic Model ………............................................18

C. Empirical Results-The Basic Model With Country Sub-Groupings .............22

D. Empirical Results-An Expanded Model With Policy and Control

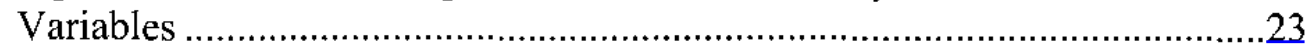

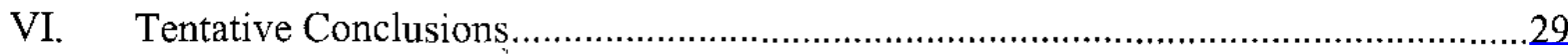

References

Text Tables

1. Share of Population Living Below US $\$ 1$ per Day …….............................................

2. Nonincome Poverty Indicators, Real GDP and Population, 1980-99 …......................

3. Sub-Saharan Africa: Poverty Trends, Conflict and Nonconflict Countries, 1972-97.

4. Nonincome Poverty Trends in SSA by Income Level and Growth Rates,

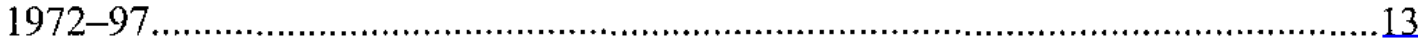

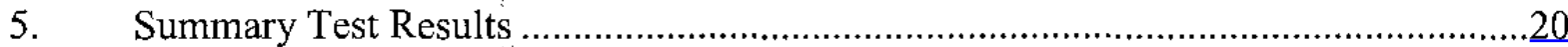

6. GDP per capita and Poverty: Basic Model with Country Groupings ………...............22

7. Summary of Expanded Instrumental Variable Model ................................................25

8. Summary of Expanded Model, Including Quality of Growth ...................................28

Box

1. Sub-Saharan Africa: Income of the Poor and National Income ................................14

Figures

1. Sub-Saharan African Countries: Life Expectancy and Per Capita GDP .....................21

2. Sub-Saharan African Countries: Infant Mortality and Per Capita GDP .....................21

3. Sub-Saharan African Countries: Primary Education Enrollment and Per Capita GDP 
Appendix Tables

1. Data Definitions and Sources........................................................................

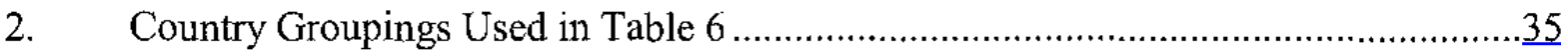




\section{Economic Growth and Poverty Reduction in Sub-Saharan Africa}

\section{INTRODUCTION}

1. Economic growth has been at the core of poverty reduction strategies in sub-Saharan Africa for decades, with higher per capita income expected to lead to improved living standards for all income groups. Recently, however, there has been mounting criticism over the focus on economic growth to reduce poverty in Africa, particularly as the number of people living below the poverty line has continued to rise. ${ }^{2}$ Some have argued that Africa is different--it is tropical, it lacks access to markets, its states are newly independent and rife with ethnic conflict, etc.and, as such, growth is not the key to poverty reduction. Others have argued that growth policies themselves are anti-poor, as macroeconomic stabilization measures reduce access to social services while increasing costs to the poor.

2. Recently, international donors and leaders of developing countries have called for an accelerated reduction in income poverty - by 50 percent, while improving infant mortality rates and primary school enrollment considerably. If these objectives are to be achieved, what development path should be pursued in Africa? To shed more light on these issues, this paper studies empirically the relationship between economic growth and poverty in sub-Saharan Africa (SSA) over the past three decades. It also analyzes the impact of the quality of growth and other factors on poverty. The study employs three standard nonincome measures of poverty to compensate for the lack of quality time series data on income of the poor in Africa and to capture a broader picture of living standards and human development than can be captured by using an income measure. The paper also assesses, to the degree possible, the relationship between mean per capita income and income of the poor, based on the limited data available.

3. This preliminary assessment is based on panel estimation of a reduced-form model of poverty, similar in structure to a number of recent macro-level growth and poverty studies. While we recognize that our study of the relationship between income and human development indicators would benefit from household level survey data, this data is not available in sufficient quantity or with sufficient quality.

4. The paper proceeds with a discussion of the link between income and poverty, followed by a review of poverty trends in Africa. The subsequent section presents the analytical approach used to study the impact of growth on poverty in Africa. Section V presents the empirical results. Section VI provides tentative conclusions.

${ }^{2}$ While the share of the population living on less than US $\$ 1$ per day in sub-Saharan Africa has remained at about $461 / 2$ percent since 1987 , the number of people living on less than US $\$ 1$ per day has risen by 74 million to an estimated 291 million in 1998 (Chen and Ravallion, 2000). 


\section{The Links Between Growth ANd Poverty}

5. The debate over the relationship between economic growth and poverty is neither new nor without controversy. However, mounting criticism of growth-oriented poverty reduction programs in Africa has led to a resurgence in empirical research in this area. At the same time, the generational leap in panel estimation techniques has allowed a much broader study of the relationship to be undertaken, particularly with increased coverage of developing countries.

\section{What is poverty?}

6. Poverty is generally viewed in terms of income. However, income provides only a partial picture, as it does not capture broader living standards or human development. In recognition of this, the World Bank defines poverty "as encompassing not only material deprivation (measured by an appropriate concept of income or consumption) but also low achievements in education and health."3 To capture this broader definition of poverty, the United Nations has constructed a composite human development index (HDI) which utilizes a weighted average of life expectancy, per capita income, and educational achievement. While a step forward, this index has a number of shortcomings. It has been criticized for having arbitrary component weights, for its selection of indicators and for its bias toward developing countries. $^{4}$

7. We employ the World Bank's broader definition of poverty in this study, including three standard human development indicators: life expectancy from birth, the infant mortality rate, and gross primary school enrollment. ${ }^{5}$ Given the controversy surrounding the United Nation's human development index, we choose to analyze each of the indicators separately. Moreover, owing to the lack of quality data on income of the poor in SSA, we focus our detailed econometric analysis on these non-income poverty measures, though we present preliminary estimates of the relationship between income and income of the poor in Box 1.

${ }^{3}$ World Development Report, 2000/2001 (page 15).

4 See the 1993 Human Development Report technical note for a more detailed discussion of problems associated with using the HDr to measure poverty.

${ }^{5}$ We use both infant mortality rates (IMR) and life expectancy (LE) to measure health. While they are understandably correlated $(0.8)$, as IMRs are an input into overall mortality rates and they both are largely derived from the same health surveys, we find the relationship has weakened over the past decade in SSA. As HIV/AIDs and other factors have reversed the gains in LE in a number of countries, IMRs continue to improve. We expect this divergence to continue, and possibly accelerate, in the coming decade. This view is confirmed in the empirical results. 


\section{Economic growth and non-income poverty (health and education)}

8. A number of studies have found income to be a key factor explaining health and education levels. Deaton (1999), in a household level study of income, health and inequality in the United States, summarizes the income-health relationship as follows: "That income should cause health through a health Engel curve is consistent with standard health capital approaches in economics in which health is produced with health care and behavioral inputs that have to compete with leisure and other expenditures for a limited budget of time and money." Deaton (2001) also notes "Furthermore, the public health literature has demonstrated reasonably convincingly that neither reverse causality nor risky behaviors (nor differential access to medical care) can account for more that a fraction of the gradient, and takes the position that there is a direct causal link from social status to health status." 6 This follows work by Wilkinson (1996) and others that show that increases in income cause improvements in health, particularly at low levels of income. Others also confirm a strong relationship between income growth and infant mortality rates. For Africa, Case (2001) confirms a causal relationship from income to health in a household level study of pensioners in South Africa. In summarizing the literature, the $2000 / 2001$ World Development Report notes that "growth improves average health attainments through its ability to reduce income poverty and permit more pro-poor social spending." A similar causal relationship has been established from income to education levels, with the World Bank concluding that "Within and between countries both the quantity and the quality of education improve with income - although quality is difficult to measures." 8

9. At the same time, there is also a large body of empirical work on human capital development and economic growth that supports the view that better health and education increase growth. Acknowledging both sides of the issue, the World Bank, as well as Ranis (2000) and others suggest that there is a two-way relationship between economic growth and human development in developing countries, with a virtuous cycle occurring when both growth and human development increase. They argue that government policies should support both economic growth and effective delivery of social services. Investigating empirically the relationship between growth and the life expectancy shortfall, Ranis finds that a 1 percentage point increase in the average growth rate of GDP per capita leads to a 2-3 percentage point reduction in the life expectancy shortfall, with a significant, but weaker, response for Africa. Ranis also finds a strong reverse relationship between improvements in human development and economic growth, supporting the view of a two-way relationship, and the possibility of both virtuous and vicious cycles.

\footnotetext{
${ }^{6}$ The gradient being the negative relationship between mortality and income.

${ }^{7}$ World Development Report, 2000/2001 (Chapter 3).

${ }^{8}$ World Development Report, 2000/2001 (Chapter 3).
} 


\section{Economic growth and income of the poor}

10. In the broadest sense, growth-oriented poverty reduction programs have assumed that economic growth benefits all segments of society without a strong bias toward (or against) one income group. To test this hypothesis, a number of recent empirical studies have investigated the direct relationship between the growth rate of the income of the poor and the median rate of growth for the country as a whole. Roemer and Gugerty (1997) in a sample of 26 developing countries find that a 1 percent increase in per capita income is correlated with a 0.9 percent increase in the income of the poorest 20 percent of the population. Dollar and Kraay (2000), employing a larger set of panel data, find a one-to-one relationship between economic growth and income of the poor. In additional, Dollar and Kraay find that economic growth policies do not directly affect the income of the poor (positively or negatively) outside their impact though the growth channel.

11. Ravallion and Chen (1997), using consecutive household expenditure surveys for a group of 42 developing countries, find that the share of the population living on less than US\$1 per day falls by 3 percent for every 1 percent increase in mean per capita income. However, they note that, while there is strong evidence that an increase in mean per capita income leads to a decline in absolute poverty, there is a strong variance across countries, indicating that countryspecific considerations are important to the impact of income growth on poverty. Ali (2000) finds that the impact of growth on poverty reduction is stronger in all other regions of the world than in Africa. He suggests, based on this regional analysis, that the impact of income growth on poverty reduction is stronger in middle and high income countries than in low income countries.

12. Many of these empirical income poverty studies, however, have not focused on Africa, largely because of data constraints. Roemer and Gugerty, for example, include only one SSA country in their study, while Ravallion and Chen, and Dollar and Kraay, include 7 observations. This has led to criticism that these findings may not reflect Africa's situation, as its countries are different (for the reasons cited above).

\section{Quality of growth and poverty}

13. While the jury is still out on the relationship between growth and inequality across countries, several recent empirical studies have found that inequality is linked with growth in low income countries. Perotti (1996) and Barro (2000) find that growth and inequality move together in low income countries. Galor and Moav (2000) find that while an increase in growth may increase inequality in the short run, this effect reverses itself over the medium run. Other empirical studies have looked at the impact of the quality of growth on poverty reduction across regions and have found income distribution and the provision of health and education services 
help explain the difference in the impact of growth on poverty across countries. ${ }^{9}$ Fielding (2001), for example, finds a causal relationship from inequality to per capita income, literacy and life expectancy in Africa.

\section{Poverty Trends in Sub-Saharan Africa (SSA)}

\section{A. Africa's Widening Poverty Gap}

14. Before discussing the empirical model and the results of the poverty and growth analysis, it is useful to review recent trends. First, as has been widely reported, efforts to reduce poverty in Africa have been disappointing over the past two decades, as Africa's poverty gap with the rest of the World has widened significantly. While the share of Africa's population earning less than US $\$ 1$ per day fell by 1.4 percentage points over the $1990-98$ period, it declined by 4 percentage points in South Asia and by 12.3 percentage points in East Asia. ${ }^{10}$ This meant that SSA's share of the world's population living below US\$1 per day increased from 19 percent in 1990 to 24 percent in $1998 .^{17}$

Table. 1. Share of Population Living Below US\$1 per Day (In 1993 PPP International Dollars) 1/

\begin{tabular}{|c|c|c|c|c|}
\hline \multirow[b]{2}{*}{. } & \multicolumn{3}{|c|}{$\begin{array}{l}\text { Share of Population } \\
\text { Living Below US } \$ 1 \text { per day }\end{array}$} & \multirow{2}{*}{$\begin{array}{l}\text { Rcal GDP Growth } \\
\text { Rate Per Capita 2/ } \\
1990-99 \text { (avg. annual) }\end{array}$} \\
\hline & 1990 & $\begin{array}{l}1998 \\
\text { Prelim. }\end{array}$ & $\begin{array}{l}\text { Change } \\
1990-98 \\
\end{array}$ & \\
\hline East Asia and Pacific & 27.6 & 15.3 & -12.3 & 5.9 \\
\hline Eastern Europe and Central Asia & 1.6 & 5.1 & 3.6 & -3.3 \\
\hline Latin America and Caribbean & 16.8 & 15.6 & -1.2 & 0.9 \\
\hline Middle East and North Africa & 2.4 & 2.0 & -0.4 & -0.1 \\
\hline South Asia & 44.0 & 40.0 & -4.0 & 3.2 \\
\hline Sub-Saharan Africa & 47.7 & 46.3 & -1.4 & -0.2 \\
\hline
\end{tabular}

1/ Source: Chen and Ravallion (2000).

2/ World Bank, World Development Report, 2000.

Includes all low- and middle-income countries in Europe and Central Asia.

\footnotetext{
${ }^{9}$ The 2000/2001 World Development Report (Chapter 3) provides a detailed review, with annotated references, of the literature on the relationship between income inequality and nonincome poverty in developing countries.

${ }^{10}$ Chen and Ravallion (2000).

${ }^{11}$ In terms of absolute numbers, 522 million people in South Asia were living below the poverty line in 1998, compared with 291 million in SSA and 278 million in East Asia and Pacific.
} 
15. In general, the change in income poverty in low- and middle-income countries during the 1990s tracked well changes in median income. In particular, strong growth in South Asia and East Asia and the Pacific was associated with sizable declines in poverty, while economic contraction in Eastern Europe and Central Asia was associated with a sizable increase in poverty. Largely stagnant economic activity in SSA, the Middle East and North Africa, and Latin America is associated with modest declines in poverty rates in these regions.

16. Infant mortality rates (IMRs) declined moderately in Africa during the 1980-98 period, although they remain substantially higher than the rest of the world. The IMR declined by 20 percent in SSA (to 92 per 1000) during this period, compared with a decline of 37 percent in South Asia, 36 percent in East Asia and Pacific and 49 percent in Latin American and the Caribbean.

17. Improvements in life expectancy in SSA have been less encouraging. During the 198098 period, life expectancy increased by only 4 percent in SSA (to 50 years) compared with an increase of 8 percent in Latin America and the Caribbean (to 70 years), and 15 percent in South Asia (to 62 years). However, the spread of HIV/AIDs was an important factor moderating the increase in life expectancy in SSA in the 1990s.

Table 2. Nonincome Poverty Indicators, Real GDP and Population, 1980-99

\begin{tabular}{|c|c|c|c|c|c|c|c|c|c|c|}
\hline & \multirow{2}{*}{\multicolumn{3}{|c|}{$\begin{array}{c}\text { Life Expectancy } \\
\text { at Birth (In ycars) }\end{array}$}} & \multirow{2}{*}{\multicolumn{3}{|c|}{$\begin{array}{l}\text { Infant Mortality } \\
\text { Rate (Per } 1000)\end{array}$}} & \multirow{2}{*}{\multicolumn{2}{|c|}{$\begin{array}{l}\text { Real GDP Growth } \\
\text { Rate per Capita (Avg.) }\end{array}$}} & \multirow{3}{*}{$\begin{array}{c}\text { GNP } \\
\text { Per Capita } \\
\text { (PPP \$) } \\
1999\end{array}$} & \multirow{3}{*}{$\begin{array}{l}\begin{array}{l}\text { Population } \\
\text { (In Millions) }\end{array} \\
1999\end{array}$} \\
\hline & & & & & & & & & & \\
\hline & 1980 & 1998 & $\%$ change & 1980 & 1998 & $\%$ change & $1980-90$ & $1990-99$ & & \\
\hline Low- and middle-income countries & 58 & 65 & 12.1 & 87 & 59 & -32.2 & 1.3 & 1.4 & 3,410 & 5,084 \\
\hline East Asia and Pacific & $\ldots$ & 69 & $\ldots$ & 55 & 35 & -36.4 & 5.7 & 5.9 & 3,500 & 1,837 \\
\hline Europe and Central Asia & 68 & 69 & 1.5 & 41 & 22 & -46.3 & 1.9 & -3.3 & 5,580 & 475 \\
\hline Latin America and Caribbean & 65 & 70 & 7.7 & 61 & 31 & -49.2 & -1.3 & 0.9 & 6,280 & 509 \\
\hline Middle East and North Africa & 59 & 68 & 15.3 & 95 & 45 & -52.6 & -1.1 & -0.1 & 4,600 & 291 \\
\hline South Asia & 54 & 62 & 14.8 & 119 & 75 & -37.0 & 3.9 & 3.2 & 2,030 & 1,329 \\
\hline Sub-Saharan Africa & 48 & 50 & 4.2 & 115 & 92 & -20.0 & -1.0 & -0.2 & 1,450 & 642 \\
\hline High-income countries & 74 & 78 & 5.4 & 12 & 6 & -50.0 & 2.0 & 1.5 & 24,430 & 891 \\
\hline Medium-income countries & 65 & 69 & 6.2 & 60 & 31 & -48.3 & 1.1 & 2.0 & 4,880 & 2,667 \\
\hline Low-income countries & $\ldots$ & 63 & $\ldots$ & 97 & 68 & -29.9 & 2.3 & 0.0 & 1,790 & 2,417 \\
\hline
\end{tabular}

Source: World Bank, World Development Indicators, 2000.

\section{B. Civil Conflict and Poverty}

18. One important factor influencing poverty trends in sub-Saharan Africa has been the escalation of civil conflict; as the number of countries in conflict increased from 6 in 1980 to 10 in 1999. Poverty trends in SSA are noticeably better when conflict countries are excluded from the totals. In a forthcoming study of 6 African countries that experienced extensive economic losses during sustained civil conflicts in the 1980s and 1990s, Moser and others find that real per capita GDP at the end of the conflict period was on average only 55 percent of the prewar level. And, while there was an initial post-war rebound in agricultural output, the destruction of 
the capital base (both physical and human) limited the extent of medium-term gains. Consequently, five years after the end of the conflict, real per capita GDP had increased on average to only about 75 percent of prewar levels.

19. Comparing poverty and income trends for conflict and non-conflict countries over the 1972-97 period, ${ }^{12}$ we find the following:

- The IMR for nonconflict countries fell by $36 \frac{1}{2}$ percent from 1972 to 1997 , compared with a decline of $251 / 2$ percent for conflict countries. And, excluding conflict countries, the infant mortality rate in SSA compares much more favorably (at 82 per 1000 in 1997) with South Asia.

- Life expectancy increased by 171/2 percent for nonconflict countries over the 1972-97 period, compared with $91 / 2$ percent for conflict countries, even though improvements in life expectancy in nonconflict countries stalled in the 1990s owing to the spread of HIV/AIDS.

- School enrollment rates also are substantially lower for conflict countries. Gross primary school enrollment increased from 61 percent in 1972 to 89 percent in 1997 for nonconflict countries, compared with an increase from 46 percent in 1972 to 66 percent in 1992 for conflict countries.

- This dichotomy in performance between conflict and nonconflict countries is also reflected in economic growth: real GDP per capita (in PPP - purchasing power parityinternational dollars) increased by an annual average rate of $5 \frac{1}{2}$ percent for nonconflict countries over the 1972-97 period, compared with 3 percent for conflict countries. For the 1982-97 period, the average annual growth rate of 2 percent for nonconflict countries was double the rate for conflict countries. Real per capita GDP (in U.S. dollars terms, converted at 1990 exchange rates) increased at an avcrage rate of 1 percent annually for nonconflict countries over the $1972-97$ period, compared with a decline of $11 / 2$ percent annually for conflict countries.

${ }^{12}$ Conflict countries comprising Angola, Burundi, Chad, Democratic Republic of the Congo, Ethiopia, Guinea-Bissau, Liberia, Mozambique, Nigeria, Rwanda, Sierra Leone, Sudan, and Uganda. These countries represent 55 percent of the population in SSA in 1990. 
Table 3. Sub-Saharan Africa: Poverty Trends, Conflict and Nonconflict Countries, 1972-97 1/

\begin{tabular}{|c|c|c|c|c|c|c|}
\hline & 1972 & 1982 & 1992 & 1997 & $\begin{array}{l}\text { Percent } \\
\text { Change } \\
1972-97\end{array}$ & $\begin{array}{l}\text { Percent } \\
\text { Change } \\
1982-97 \\
\end{array}$ \\
\hline \multicolumn{7}{|c|}{ Infant mortality rate (per 1000) } \\
\hline Conflict countries & 152 & 132 & 128 & 113 & -25.7 & -14.4 \\
\hline Nonconflict countries & 129 & 104 & 86 & 82 & -36.4 & -21.2 \\
\hline \multicolumn{7}{|c|}{ Life expectancy (in years from birth) } \\
\hline Conflict countries & 42 & 45 & 44 & 46 & 9.5 & 2.2 \\
\hline Nonconflict countries & 46 & 51 & 54 & 54 & 17.4 & 5.9 \\
\hline \multicolumn{7}{|c|}{ Primary school enrolltnent (gross percent) } \\
\hline Confict countries & 46 & 72 & 66 & $\ldots$ & 43.5 & -8.32 \\
\hline \multirow[t]{2}{*}{ Nonconflict countries } & 61 & 84 & 82 & 89 & 45.9 & 6.0 \\
\hline & 1972 & 1982 & 1992 & 1997 & \multicolumn{2}{|c|}{$\begin{array}{l}\text { Average Annual } \\
\text { Rate of Growth }\end{array}$} \\
\hline \multicolumn{7}{|c|}{ Real per capita GDP (in PPP\$) } \\
\hline Conflict Countries & 499 & 855 & 1,019 & 1,110 & 3.2 & 1.0 \\
\hline Non-conflict Countries & 723 & 1,653 & 2,333 & 2,771 & 5.5 & 2.1 \\
\hline
\end{tabular}

\section{Economic Growth and Poverty}

20. In addition to civil conflict, anemic economic development has also played an important role in limiting poverty reduction in Africa. To better assess the relationship between economic growth and poverty reduction, we decompose 46 SSA countries into nine groups, determined by initial income level (low, medium, high) ${ }^{13}$ and average economic growth rate (low, moderate, high). ${ }^{14}$ Looking at the $3 \times 3$ matrix of countries (Table 4), we see that countries with high initial income levels exhibit a much faster average rate of improvement in IMRs, life expectancy, and gross primary school enrollments than low-income countries. We also see that countries with higher growth rates within each income group experience faster rates of decline in poverty. (Table 4 presents average annual rates of change in poverty indicators over the 1972-97 period for each of the 9 income/growth rate combinations for each poverty indicator.)

\footnotetext{
${ }^{13}$ The three income groups are based on 1972 real per capita GDP (PPP\$): 15 low-income (below \$370), 16 medium-income (\$370-\$610), and 15 high-income (above \$610) countries.

${ }^{14}$ The three growth rate groups are based on average annual 1972-97 real per capita GDP (PPP\$) growth rates: 13 low-growth (4 percent and below), 18 medium-growth (4.1-6 percent), and 8 high-growth (above 6 percent) countries.
} 
21. With respect to infant mortality rates, we find that low-income countries with low growth rates experienced an average annual decline in their IMR of 0.5 percent during 1972-97, compared with an average rate of decline of 1.3 percent for medium-income countries with moderate growth rates and 3.1 percent for high-income countries with high growth rates. In addition, IMRs in most cases declined faster as economic growth rates increased, for each of the three income groups. 


\section{$-13-$}

Table 4. Nonincome Poverty Trends In SSA by Income Level and Growth Rates, 1972-97 1/

Infant Mortality Rates

\begin{tabular}{llll}
$\begin{array}{l}\text { Initial } \\
\text { Income Group }\end{array}$ & $\begin{array}{l}\text { Low- } \\
\text { Growth } \\
\text { Countries }\end{array}$ & $\begin{array}{l}\text { Moderate- } \\
\text { Growth } \\
\text { Countries }\end{array}$ & $\begin{array}{l}\text { High - } \\
\text { Growth } \\
\text { Countries }\end{array}$ \\
\hline Medium-income countries & & & \\
High-income countries & & &
\end{tabular}

Life Expectancy

\begin{tabular}{llll}
\hline Growth Rate & Low- & Moderate- & High - \\
Initial Group & Growth & Growth & Growth \\
Income Group & Countries & Countries & Countries \\
\hline
\end{tabular}

Low-income countries

\section{Illiteracy Rate}

\begin{tabular}{llll}
\hline Growth Rate & Low- & Modcrate- & High - \\
Initial & Growth & Growth & Growth \\
Income Group & Counties & Countries & Countries \\
\hline
\end{tabular}

Low-income countries

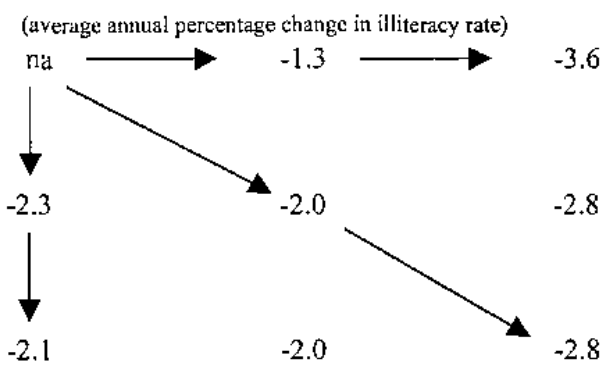

High-income countries

$$
-2.1
$$

$-2.0$

1/ Income levels based on 1972 real PPP GDP per capita: low income (less than \$370), medium income ( $\$ 370-\$ 610$ ), and high income (greater than $\$ 610)$. Growth rates based on average annual increase in real PPP GDP per capita during 1972-97: low growth (4 percent and below), medium growth (4.1-6 percent), and high growth (greater than 6 percent). 
22. Improvements in life expectancy also show a strong correlation with income levels and economic growth rates. The average annual change in life expectancy during 1972-97 for lowincome, low-growth countries was a decline of 0.9 percent, compared with an increase of 0.6 percent for medium-income, medium-growth countries and 0.7 percent for high-income, highgrowth countries. This relationship, however, breaks down in the case of middle income countries experiencing high growth rates. This reflects, to a large degree, the sizable impact of rising HIV/AIDS prevalence rates on life expectancy in southern and east Africa.

23. The decline in illiteracy rates also seems to be closely correlated to improvements in income levels and economic growth rates, though the relationship is not as pronounced within income groups as that for infant mortality rates and life expectancy. Nonetheless, illiteracy rates in medium income countries with moderate growth rates declined by an average annual rate of 2.0 percent over the $1972-97$ period, compared with an average annual decline of 2.8 percent for high-income, high-growth countries.

\section{Box 1. Sub-Saharan Africa: Income of the Poor and National Income}

While this paper focuses on the relationship betwecn cconomic growth and non-income poverty measures, we also find a strong relationship between national income and income of the poor, based on a much smaller panel of 44 household expenditure surveys cover 31 SSA countries. We find (using ordinary least squares) that a 10 percent increase in per capita income leads to a 3.4 percent decline in the share of the population living below the national head count poverty line.

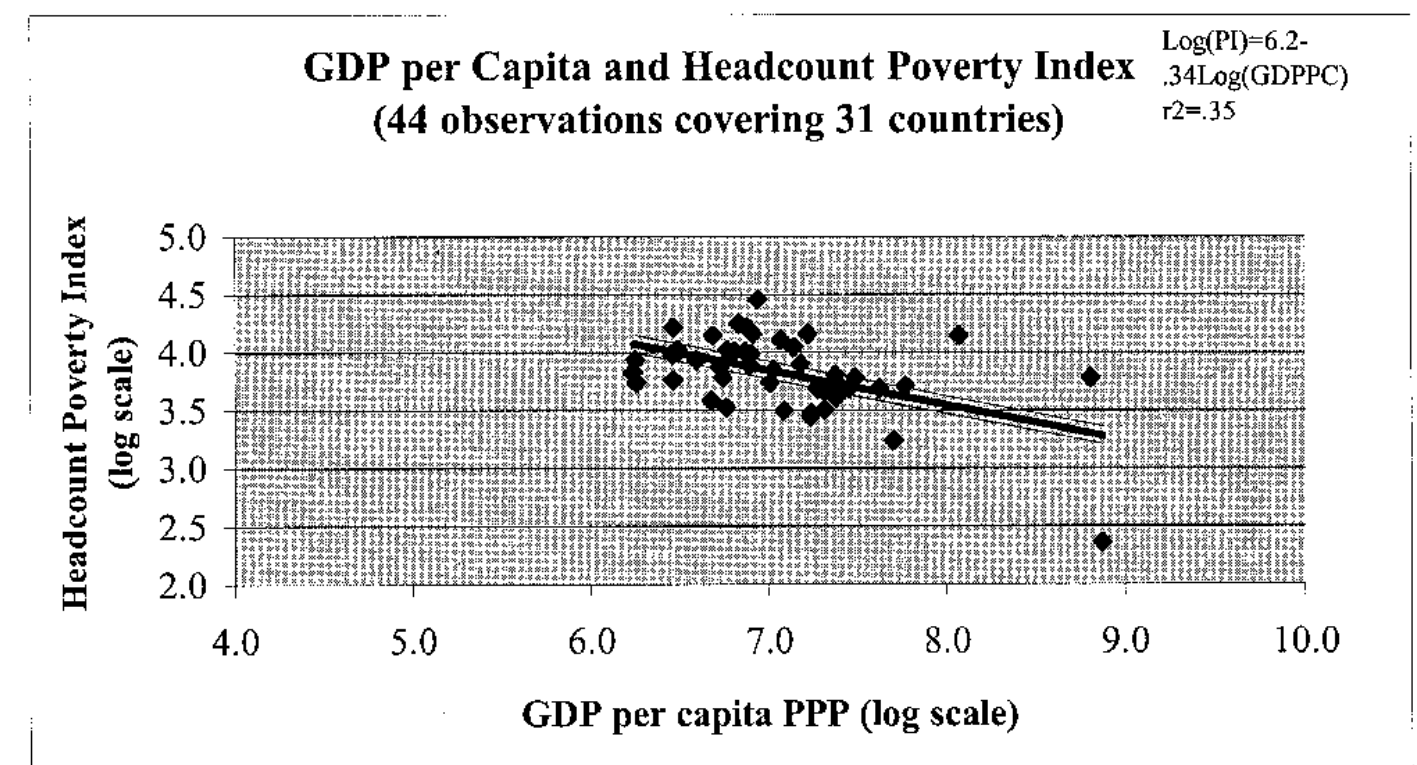

Understandably, this relationship may be biased by the limited number of household surveys and countries used. For this reason, we also revicw the correlation between national head count poverty indices and the nonincome measures of poverty used in this study to see if a nonincome poverty indicator might be uscd as a proxy for income poverty. We find that infant mortality rates are correlated with the national head count poverty index (0.8), suggesting that the relationship between changes in real GDP and infant mortality rates might be used as a proxy for the relationship between changes in income of the poor and median income. 


\section{HIV/AIDS and Poverty}

24. The rapid spread of HIV/AIDs in Africa in the 1980s and 1990s has significantly reduced life expectancy in a number of countries. Haacker (2001) provides a detailed review of the impact of HIV/AIDs on health outcomes in southern Africa over the past decade, and makes preliminary projections of the impact of HIV/AIDs on GDP growth in these countries over the medium term. As noted in his study, according to estimates by the U.S. Bureau of the Census, the adult HIV/AIDS prevalence rate in 1999 was 8.6 percent in Sub-Saharan Africa, compared with 0.2 percent globally. In Botswana, for example, with an adult prevalence rate of 36 percent, life expectancy is estimated by the U.S. Bureau of the Census to have fallen by about 20 years from 1988 to 1998.

\section{FRAMEWORK FOR EMPIRICAL ANALYSIS-METHOdology}

25. Our theoretical framework for the empirical analysis of the impact of income on nonincome poverty is based on the discussion in Section II above:

- First, we assume that there is a two-way channel between human development and growth, as discussed in Ranis and others (2000). In the first channel, human development increases labor productivity and, subsequently, growth, while in the second channel, income growth increases family and state resources that can be applied toward increasing human development (a key component of an individual or family's welfare function).

- Second, we assume that, the second channel-from income to health and education levels-dominates in low income countries as discussed in Section II above. Several recent cross-country growth studies have also shown that the relationship from human capital development (education and health) to income is weak in low income countries. Duffy and Papageorgiou (2000), for example, find that, for a group of 82 countries, physical and human capital adjusted labor have a low substitutability in low income countries vs. a high substitutability in high income countries, thus underscoring the role of capital accumulation (not human capital development) in the growth equation in low income countries. Funk and Stulik (2000) also find low income countries to be characterized by physical capital accumulation, while high income countries are characterized by human capital development.

- Third, we assume that while growth is necessary to reduce poverty, it is not sufficient. As discussed in the previous section, the quality of growth (in terms of inequality and the provision of social services) and other control variables are also important factors explaining improvements in nonincome poverty. 


\section{The model}

26. The empirical analysis employs a panel approach, and is based on an extended version of the Dollar and Kraay model, where

$$
M_{c t i}^{P}=\alpha_{1}+\alpha_{2} * Y_{c t}+\alpha_{3}{ }^{*} X_{c t}+u_{c}+v_{\mathrm{t}}+e_{c t} .
$$

$M_{c t i}^{P}$ represents the measure of poverty for country $c$, time $t$, and measurement $i$; $Y_{c t}$ represents mean per capita income for country $c$ and time period $t ; X_{c t}$ represents other nonincome factors affecting poverty for country $c$ and time period $t$; and $u_{c}, v_{t}$, and $e_{c t}$ represent country-specific, time-specific and common error terms.

27. A baseline log-linear and first-difference ordinary least squares (OLS) model will first be estimated, with the regressions then corrected for heteroscedasticity using a standard generalized least squares (GLS) estimator. The model will also be estimated as a system with instrumental variables using two-stage least squares (2SLS) to correct for possible reverse causality from poverty indicators to income. In this regard, we will instrument for mean income with lagged mean income. ${ }^{15}$ Instrumental variables will also correct for omitted variables to the degree to which the instrumental variables are uncorrelated with the omitted variables. We maintain the same variable transformation for $X$ 's regardless of our specification for $M^{P}$ 's and $Y$ 's. For example, in the case of life expectancy, the log-level specification is written as follows:

$$
\ln (\text { life expectancy) })_{c t}=\alpha_{1}+\alpha_{2} * \ln (\text { per capita GDP })_{c t}+\alpha_{3} * X_{c t}+u_{c}+v_{t}+e_{c t} \text {, }
$$

where $\ln (x)$ represents the natural logarithm of variable $x$. The growth rate specification is written as follows: ${ }^{16}$

$$
\begin{aligned}
& {\left[\ln (\text { life expectancy) })_{c t}-\ln (\text { life expectancy })_{c t-1}\right]=\alpha_{1}+\alpha_{2}^{*}\left[\ln (\text { per capita GDP })_{c t}\right.} \\
& \left.(\text { per capita GDP })_{c t-1}\right]+\alpha_{3}^{*} X_{c t}+\left[\left(u_{t}-u_{t-1}\right)+\left(v_{t}-v_{t-1}\right)+\left(e_{c t}-e_{c t-1}\right)\right]
\end{aligned}
$$

28. We are particularly interested in the parameter $\alpha_{2}$ from equations (1)-(3). In the log-level specification (equation 2), this parameter is considered as the elasticity of poverty measures with respect to mean income. In the growth specification (equation 3), the parameter measures the impact of income growth on the percentage change in poverty measures. As we have a panel

\footnotetext{
${ }^{15}$ We use current income as the dependent variable assuming that the change in current income best explains the change in health status between the current and past period.

${ }^{16}$ With the first difference in log level approximating a compounded growth rate: $\left(X_{t}-X_{t-1}\right) /$ $\left(X_{t-l}\right) \approx \ln \left(X_{t}\right)-\ln \left(X_{t-l}\right)$. Of course, $X_{t}$ and $X_{t-l}$ cannot be far apart for this close approximation to hold.
} 
(or pooled time-series) data set, this difference is subtle and requires a close, case-by-case, examination.

29. First, consider a pooled least-squares specification without taking into account fixed effects, ${ }^{17}$ that is, a simple OLS that does not take into account cross-country and time-trend differences. Using OLS, the log-level model parameter $\alpha_{2}$ is the income elasticity of poverty measure $M$, where a 1 percent higher income level is associated with an $\alpha_{2}$ percent change in poverty. This elasticity relationship applies both across and within countries, with the following two interpretations possible: (a) if we compare two countries, one with mean income level $Y$ and the other with level $1.01^{*} Y$, and if we know that the nonincome poverty measure in the former country is $\mathrm{M}$, then it is reasonable to expect that the latter country's nonincome poverty measure is $\left(1+\alpha_{2} / 100\right)^{*} M$; and (b) we can also consider this elasticity as the time dimension evolution for one country. Suppose a country with mean income level $Y$ grows by 1 percent; then we can expect $M$ to increase by $\alpha_{2}$ percent.

30. In a growth rate specification, however, only interpretation (b) is available. In equation (3), the parameter $\alpha_{2}$ tells us that if a country's income grows at $\gamma$ percent in a period, the poverty measure grows at $\left(\alpha_{2}\right)^{*}(\gamma)$ percent more. This specification in OLS is country specific. It captures "within-country" effects. However, if the relationship between $M$ and $Y$ were log linear "across" countries and "within" a country, then the coefficients from these two specifications, (2) and (3), would coincide with each other. Our estimation results support this assumption of log linearity across and within countries.

31. Second, in a fixed-effect model, the cross-sectional interpretation (a) must also disappear from the log-level specification. The parameter $\alpha_{2}$ with a fixed-effect model captures within country effects. In our study, the regressions are corrected for heteroscedasticity using a cross-sectional weighted GLS estimator.

32. The study will also assess the impact of the quality of growth on poverty reduction, proxied by the degree of inequality and the provision of social services. To assess the impact of macroeconomic stabilization and growth policies on poverty, the impact of inflation, government expenditure, openness to external trade, and external terms of trade will also be reviewed. In addition, the impact of a number of important nonpolicy variables will be assessed, including civil conflict, geography (access to the sea), and civil and institutional freedoms. We will also assess the impact of "the tropics" on poverty indicators, by including a dummy variable representing a country's latitude.

${ }^{17}$ Correcting for random effects proves not to be necessary. 


\section{EMPIRICAL RESUlts}

\section{A. Causal Relationship Between Growth and Non-Income Poverty}

33. We first look at the direction of causality between income and nonincome poverty (health and education), to see what the data itself may reveal. While we can not undertake a Granger-like causality test, we do look at a vector autoregression (VAR) model of income and poverty to test whether lagged income is a significant explanatory variable in the poverty equations and whether lagged poverty variables are significant explanatory variables in the income equations.

34. With approximately 220 observations (46 countries), we estimate the following VAR for income and poverty $\left(\mathrm{po}_{\mathrm{i}}\right)$ indicators, where $\mathrm{i}$ includes life expectancy (LE), infant mortality rates (IMR) and school enrollment (SE), with a lag length of 3 (the maximum possible give the time series limitations):

$$
\begin{aligned}
& \ln (\text { income })_{c t}=\alpha_{1}+\alpha_{2} * \ln \left(\mathrm{po}_{\mathrm{i}}\right)_{c t-1}+\alpha_{3} * \ln \left(\mathrm{po}_{\mathrm{i}}\right)_{c t-2}+\alpha_{4} * \ln \left(\mathrm{po}_{\mathrm{i}}\right)_{c t-3}+\alpha_{5}{ }^{*} \ln (\text { income })_{c t-1}+ \\
& \alpha_{6}{ }^{*} \ln (\text { income })_{c t-2}+\alpha_{7} * \ln (\text { income })_{c t-3}+\alpha_{8} * X_{c t}+u_{c}+v_{t}+e_{c t} \\
& \ln \left(\mathrm{po}_{\mathrm{i}}\right)_{c t}=\alpha_{1}+\alpha_{2} * \ln \left(\mathrm{po}_{\mathrm{i}}\right)_{c t-1}+\alpha_{3} * \ln \left(\mathrm{po}_{\mathrm{i}}\right)_{c t-2}+\alpha_{4} * \ln \left(\mathrm{po}_{\mathrm{i}}\right)_{c t-3}+\alpha_{5} * \ln (\text { income })_{c t-1}+ \\
& \alpha_{6} * \ln (\text { income })_{c t-2}+\alpha_{7} * \ln (\text { income })_{c t-3}+\alpha_{8} * X_{c t}+u_{c}+v_{t}+e_{c t}
\end{aligned}
$$

35. Using pooled least squares, with fixed effects, a time dummy and White heteroscedasticity-consistent standard errors and covariance, we test the null hypothesis that all the $\mathrm{po}_{\mathrm{i}}$ coefficients $\left(\alpha_{2} \alpha_{3}\right.$ and $\left.\alpha_{4}\right)$ in the income equation (4) are zero against the alternative hypothesis that all the income coefficients $\left(\alpha_{5} \alpha_{6}\right.$ and $\alpha_{7}$ in the po i equation (5) are zero. We find that lagged income variables are significant explanatory variables in the life expectancy equation (at the 10 percent confidence level), and significant in the infant mortality rate and primary school enrollment equations (at the 5 percent confidence level). However, we find that neither lagged life expectancy, lagged infant mortality rate or lagged primary school enrollment rate variables are significant explanatory variables in the income equation. While this does not represent a causality test, it does give us some indication of the significant role income plays in poverty reduction, and the less significant role health and education play in income growth in SSA, over a time horizon of less than one generation.

\section{B. Empirical Results-The Basic Model}

36. We first estimate the basic model (equation 1) using OLS, GLS and 2SLS techniques, with and without fixed effects, as described in Section IV above, where poverty is strictly a function of income:

$$
\operatorname{Ln}(\text { poverty measure })_{c t}=\alpha_{1}+\alpha_{2}{ }^{*} \operatorname{Ln}\left(\text { per capita GDP) } c t+u_{c}+v_{t}+e_{c t}\right.
$$

Instrumental variables are used to eliminate possible feedback effects from poverty measures onto income, with lagged income an instrument for current income. The GLS and 2SLS log- 
level equations are also estimated with a time trend dummy to examine the cross-sectional implications of the results. Equation 6 is then also estimated in first-difference form for each of the poverty measures, to test the robustness of the results.

37. Preliminary results are summarized in Table 5 below, with log-linear trend charts in Figures 1-3. We find that a 10 percent increase in real per capita GDP (in PPP international dollars) leads to a 1 percent increase in life expectancy, a 3-4 percent decline in IMRs, and a $31 / 2-4$ percent increase in the rate of gross primary school enrollment. These results prove to be robust for OLS, GLS, and 2SLS log-level equations, including and excluding fixed effects. These elasticities also prove to be robust in the log-linear equations after a time trend has been extracted and, additionally, when the baseline model has been estimated in first-difference form. 
Table 5. Summary Test Results

\begin{tabular}{|c|c|c|c|c|c|c|c|c|}
\hline & \multicolumn{6}{|c|}{ Log Levels $1 /$} & \multicolumn{2}{|c|}{ Growth Rates $2 /$} \\
\hline & \multicolumn{2}{|r|}{ OLS } & \multirow{2}{*}{$\begin{array}{c}\text { GLS } \\
\text { with } \\
\text { time trend }\end{array}$} & \multicolumn{3}{|c|}{ Instrumental Variables (IV) } & \multirow[t]{2}{*}{ GLS } & \multirow[t]{2}{*}{ IV } \\
\hline & $\overline{\mathrm{OLS}}$ & $\begin{array}{l}\text { OLS with } \\
\text { time trend }\end{array}$ & & IV & $\begin{array}{c}\text { IV with } \\
\text { tixed effects }\end{array}$ & $\begin{array}{l}\text { IV with } \\
\text { time trend }\end{array}$ & & \\
\hline \multicolumn{9}{|c|}{ Dependent variable: $\operatorname{Ln}$ (life expectancy) } \\
\hline Ln (per eapita GDP) & $\begin{array}{c}0.11^{*} \\
(0.008)\end{array}$ & $\begin{array}{c}0.11 \\
(0.009)\end{array}$ & $\begin{array}{r}0.12^{m} \\
(0.004)\end{array}$ & $\begin{array}{c}0.12 \\
(0.004)\end{array}$ & $\begin{array}{c}0.09 * \\
(0.014)\end{array}$ & $\begin{array}{c}0.11^{*} \\
(0.011)\end{array}$ & $\begin{array}{r}0.08 * \\
(0.006)\end{array}$ & $\begin{array}{r}0.12 \\
(0.004)\end{array}$ \\
\hline Number of observations & 271 & 271 & 271 & 227 & 227 & 227 & 225 & 227 \\
\hline Adjusted $R$-squared & 0.40 & 0.40 & 0.40 & 0.36 & 0.84 & 0.38 & 0.40 & 0.36 \\
\hline \multicolumn{9}{|c|}{ Deperident variable: Ln (infant mortality rate) } \\
\hline Ln (per capila GDP) & $\begin{array}{c}-0.35 * \\
(0.024)\end{array}$ & $\begin{array}{c}-0.33^{*} \\
(0.027)\end{array}$ & $\begin{array}{c}-0.33 * \\
(0.010)\end{array}$ & $\begin{array}{c}-0.37^{*} \\
(0.029)\end{array}$ & $\begin{array}{c}-0.39 * \\
(0.028)\end{array}$ & $\begin{array}{c}-0.35 * \\
(0.031)\end{array}$ & $\begin{array}{c}-0.33^{*} \\
(0.010)\end{array}$ & $\begin{array}{c}-0.37 * \\
(0.029)\end{array}$ \\
\hline Number of observations & 271 & 271 & $27 !$ & 228 & 228 & 228 & 271 & 228 \\
\hline Adjusted $R$-squared & 0.44 & 0.44 & 0.44 & 0.44 & 0.93 & 0.44 & 0.44 & 0.44 \\
\hline \multicolumn{9}{|c|}{ Dependent variabie: Ln (primary school enrollment) } \\
\hline Ln (per capila GDP) & $\begin{array}{c}0.39 \\
(0.039)\end{array}$ & $\begin{array}{c}0.399^{*} \\
(0.046)\end{array}$ & $\begin{array}{r}0.37^{*} \\
(0.020)\end{array}$ & $\begin{array}{c}0.36 * \\
(0.047)\end{array}$ & $\begin{array}{c}0.36 * \\
(0.050)\end{array}$ & $\begin{array}{c}0.37 \\
(0.050)\end{array}$ & $\begin{array}{c}0.37 * \\
(0.020)\end{array}$ & $\begin{array}{r}0.36 \\
(0.047)\end{array}$ \\
\hline Number of observations & 237 & 237 & 237 & 195 & 195 & 195 & 237 & 195 \\
\hline Adjusted $R$-squared & 0.29 & 0.29 & 0.29 & 0.23 & 0.87 & 0.23 & 0.29 & 0.23 \\
\hline
\end{tabular}

Notes: () standard error, * denotes significance at 1 percent level, ** denotes significance at 5 percent, $* * *$ denotes significance at 10 percent. Based on panel data for 46 countries over $1972-97$ (see Appendix for description of data).

OL.S = Ordinary least squares.

$\mathrm{FE}=$ fixed effects (country invariant).

GLS = generalized least squares estimator where covariance matrix is corrected for cross-section weights.

IV = the instrumental variable estimator using two stage least squares method when IV is the lagged value in In(per capita GDP).

The first stage equation is $\ln$ (per capita GDP) $=0.67+0.94 * \ln$ (per capita GDP)(-1). $R$-squared from this first-stage equation is 0.93 .

Time trend obtained by adding time trend variable $=(1,2,3,4,5,6)$ as control.

1/ Equations in log levets: $\ln$ (infant mortality rate) $=\mathrm{c}-\mathrm{a} \ln$ (per capita GDP) + error term.

$2 /$ Equations in growth fomulation: $d($ ln infant mortality rate $)=c+$ ald $(\ln$ per capita GDP) + a2 (time trend) + error term. 
Figure 1. Sub-Saharan African: Life Expectancy and Per Capita GDP (1977-97, in log scale)

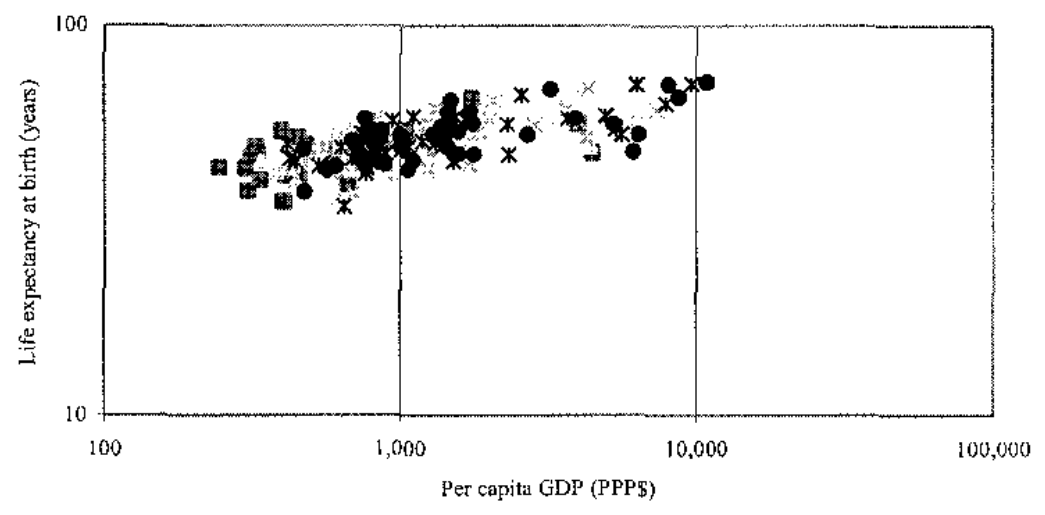

Figure 2. Sub-Saharan African Countries: Infant Mortality and Per Capita GDP (1977-97, in log scale)

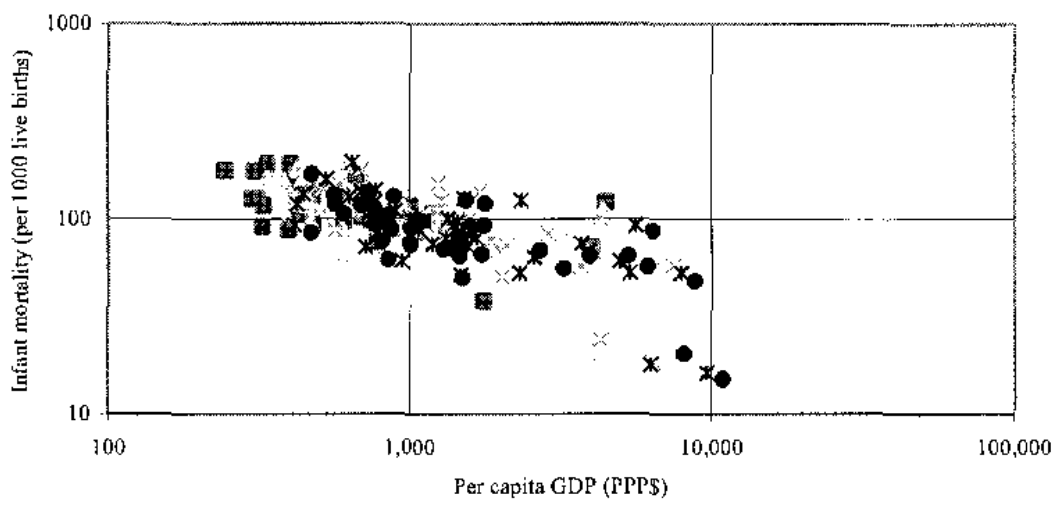

Figure 3. Sub-Saharan African Countries: Primary Education Enrolment and Per Capita GDP (1975-95, in log scale)

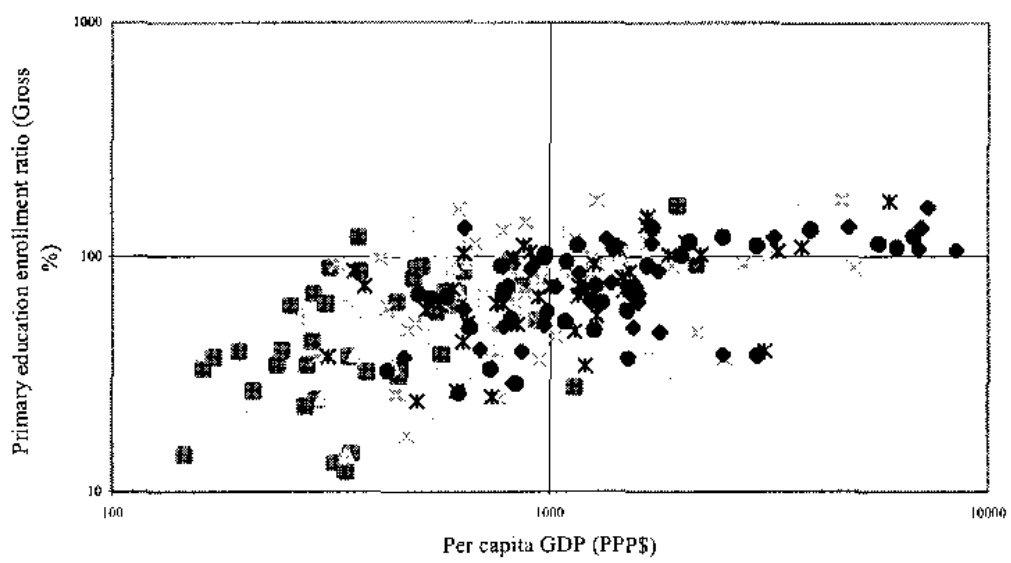

Source: World Bank, World Development Indicators; and IMF, World Economic Outlook. 


\section{Empirical Results-The Basic Model With Country Sub-Groupings}

38. Before expanding the basic model to include specific policy and control variables, we would like first to try to extract more information on the income elasticities of these poverty indicators with respect to important country sub-groupings, including low and high income, slow and fast growth, conflict and non-conflict counties, and adjusters and non-adjusters. Table 6 summarizes the empirical results for each of the country groupings, compared with the baseline model.

Table 6. GDP per capita and and Poverty: Basic Model with Country Groupings $1 /$

(Gencralized least squares estimation with lagged income and time trend)

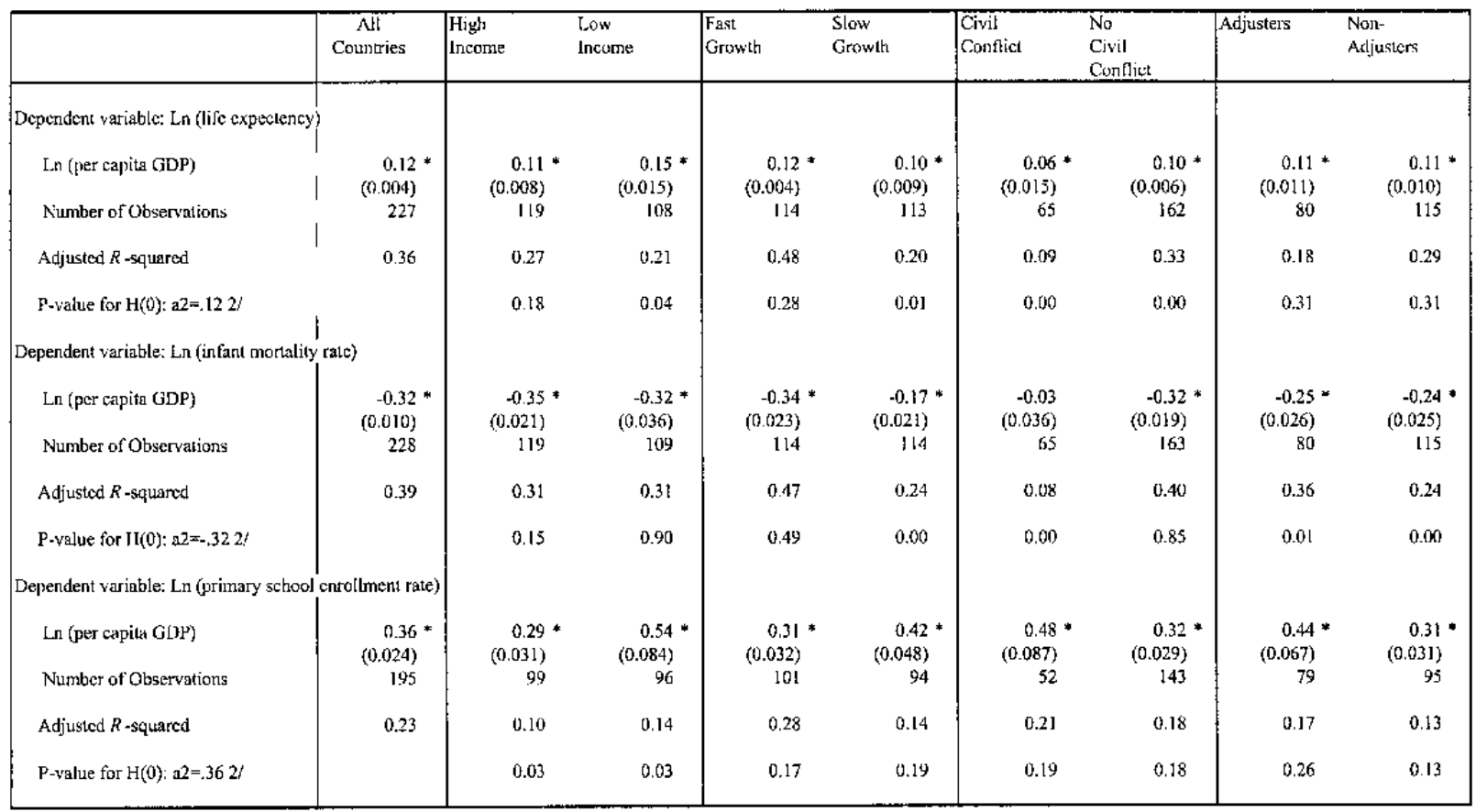

Notes: based on panel data for 46 countries, 1972-1997, () stindiril error,

* denotes signifcance al 1 percent level,

** denoles significance at 5 percent level,

*** denotes significance al 10 percent level.

1/ Appendix provides list of countries included in each country grouping.

2/ Tests the null hypothesis that the col:[Ticent on the income variable (ln(per capita GDP)) in the specific sub-group is cqual to the inconic coefficent

in the regressions for all countries.

Reports P-value for F-test, with null hypothesis rejected at $5 \%$ level, ir P-value below 0.05 and rcjected at $1 \%$ level if P-value below 0.01 .

39. Splitting the panel of 46 countries into two groups based on income, we find that economic growth has a significantly stronger impact on life expectancy and primary school enrollment in low-income countries than in high-income countries. This seems to support our prior assumption that the causal relationship from income to health and education is stronger in low income countries, though there is no significant difference between the baseline case and high/low income countries for IMRs. The stronger impact of income in low-income countries is particularly apparent for primary school enrollment, where a 1 percent increase in real GDP per capita is correlated with a 0.54 percent increase in school enrollment for low-income countries, 
versus a 0.29 percent increase for high-income countries. This, however, may be partially explained by the large share of high-income countries that have gross primary school enrollment rates above 100 percent, and could be specifically addressed in the formulation of the model in future work.

40. For fast-growth versus slow-growth countries, we find no significant difference in the impact of economic growth on life expectancy, while we find that slow-growth countries show a much weaker decline in infant mortality rates for each percentage point increase in income (an elasticity of -0.34 for fast-growth countries vs. -0.17 for slow-growth countries). Slow-growth countries, however, show a stronger increase in primary school enrollment for a given increase in income than fast-growth countries.

41. With respect to civil conflict ${ }^{18}$, we find that nonconflict countries show a significantly stronger improvement in life expectancy for each percentage point increase in income than conflict countries (an elasticity of 0.1 versus one of 0.06 ). This is also the case for infant mortality rates, where income is not a significant factor in reducing IMRs for conflict countries, while the elasticity is -0.32 for nonconflict countries. We find this result for IMRs intuitively appealing, as nonincome factors likely outweigh changes in income in these conflict countries. We find no significant difference in the income elasticity of school enrollment for conflict and nonconflict countries.

42. We find that countries consistently implementing structural adjustment programs do not exhibit significantly different elasticities from nonadjusters, with the exception that adjusters show a stronger improvement in school enrollment for a given increase in income. ${ }^{19}$ These results support the view that adjustment programs do not, in and of themselves, have a negative impact on poverty reduction or human development. On the contrary, based on numerous pervious studies, African countries consistently implementing structural adjustment programs should expect higher growth rates over the medium term and, consequently, lower poverty.

\section{Empirical Results-An Expanded Model with Policy and Control Variables}

\section{Expanded model-with macro policy and control variables}

43. We now expand the basic model above to study the impact of macroeconomic policies and non-quality of growth control variables on poverty. The policy variables tested include openness to foreign trade (exports plus imports/GDP), inflation (log[1+rate of inflation]), terms of trade (index, 1995=100), and government consumption (government consumption/GDP). The

${ }^{18} 13$ conflict countries include Angola, Burundi, Chad, Democratic Republic of the Congo, Ethiopia, Guinea-Bissau, Liberia, Mozambique, Nigeria, Rwanda, Sierra Leone, Sudan, and Uganda.

${ }^{19}$ We take the definition of adjusters from Ghura and Hadjimichael (1996), with adjuster and nonadjuster country groupings excluding nonprogram surveillance countries. 
control variables include civil war ( 1 if a civil conflict occurred during the five-year period, 0 otherwise), freedom index (rated on a scale from 2-14 for each five-year period, with 2 the most free), landlocked (a value of 1 if country is landlocked, 0 otherwise), island countries (a value of 1 if country is an island, 0 otherwise), and time trend (with each period given a value from 1 to 6). The value of each exogenous variable was tested separately with only the income variable, then together as a group. A parsimonious formulation of the regressions using 2SLS with instrumental variables for each poverty indicator is presented in Table $7 .{ }^{20}$

${ }^{20}$ We use a log-linear model for the analysis of the extended models. This seems plausible given the fact that the coefficients in the log-level and growth equations in the basic model are consistent in magnitude. In addition, we do not want to loose valuable information in a growth formulation, given the short time series available and the fact that the underlying relationship is from income levels to health and education levels. Thirdly, we detrend the series to address potential problems of spurious trend relationships. 
Table 7. Summary of Expanded Instrumental Variable Model 1/

\begin{tabular}{|c|c|c|c|}
\hline & $\begin{array}{l}\ln (\text { life } \\
\text { expectency) }\end{array}$ & $\begin{array}{l}\text { Ln (infant } \\
\text { mortality } \\
\text { rate) }\end{array}$ & $\begin{array}{l}\text { In (primary } \\
\text { school } \\
\text { enrollment) }\end{array}$ \\
\hline \multicolumn{4}{|l|}{ Basic model } \\
\hline In (per capita GDP) & $0.089 *$ & $-0.311 *$ & $0.322 *$ \\
\hline Time trend & & & $0.06 *$ \\
\hline \multicolumn{4}{|l|}{ Macro-related policy variables } \\
\hline Openess to trade (exports+imports/GDP) & & & $0.003 *$ \\
\hline Inflation rate $(1+$ inflation $)$ & & & $0.718 *$ \\
\hline Terms of trade $(1995=100)$ & & $0.0005 * *$ & \\
\hline \multicolumn{4}{|l|}{ Government expenditure/GDP } \\
\hline \multicolumn{4}{|l|}{ Control variables $2 /$} \\
\hline Civil conflict & $-0.051 *$ & $0.0413 /$ & \\
\hline Freedom index & $-0.0056 * *$ & $0.0219 *$ & \\
\hline \multicolumn{4}{|l|}{ Landlocked countries } \\
\hline Island countries & $0.134 *$ & $-0.364 *$ & $0.257 * *$ \\
\hline Adjusted R-squared & 0.54 & 0.562 & 0.35 \\
\hline Total panel (unbalanced) observations & 224 & 225 & 179 \\
\hline Observations per cross section (country) & 4 & 4 & 4 \\
\hline Number of cross sections (countries) used & 46 & 46 & 44 \\
\hline
\end{tabular}

\footnotetext{
Note: * denotes significance at the 1 percent level, ** denotes significance at the 5 percent level, and *** denotes significance at the 10 percent level.
}

1/ This table reports the results of adding the indicated control variables to the instrumental variable estimator using two stage least squares method when IV was the lagged value in In(per capita GDP). The first stage equation is $\ln$ (per capita GDP) $=0.67+0.94^{*} \ln ($ per capita GDP)(-1). $\mathrm{R}$-squared from this first-stage equation is 0.93 .

2/ See Appendix for definition of control variables.

3 / Individually significant with income variable, but not significant in model form.

44. The macroeconomic policy variables were not found to have a significant negative impact on poverty, with the exception of (exogenous) terms of trade shocks on IMRs. These results are consistent with Dollar and Kraay (2000), who find that macroeconomic policy variables do not have a direct impact on income of the poor, working instead (as intended) through their impact on economic growth. This is an important verification of the basic tenets of growth-oriented poverty reduction programs in Africa: macroeconomic stabilization and reform increases economic growth, which, in turn, reduces poverty; there is no significant additional impact of the macroeconomic policies on poverty. Many of the control variables, however, are 
found to have a direct impact on poverty. This is consistent with our prior assumption, as macro policies are already captured in the income variable.

45. As we saw in the basic model, a 10 percent increase in income will lead to a 1 percent increase in life expectancy. In addition, we find that civil conflict and low levels of civil and institutional freedom significantly reduce life expectancy for a given level of income. We also find that macroeconomic variables do not have a direct impact on life expectancy, outside the growth channel. In addition, contrary to recent criticism, the high percentage of landlocked countries in SSA does not explain poverty: we find no significantly difference in life expectancy between landlocked and other countries. We do, nonetheless, find that island countries demonstrate a lower level of poverty than mainland countries for a given income level.

46. The regression results are similarly strong for IMRs. As with the basic model, a 10 percent increase in income is associated with a 3 percent decline in IMRs. We find also that civil conflict and the lack of civil and institutional freedom increases these rates. In addition, we find, somewhat surprisingly, that a substantial improvement in the external terms of trade modestly raises IMRs. It is not immediately clear what if any mechanism may be in play to allow an improvement in the external terms of trade to negatively impact infant mortality rates, or whether this is a spurious relationship. Additional work is required here to understand the relationship. Similar to the results for life expectancy, we find no difference in IMRs between landlocked and other countries, while island economies exhibit lower IMRs than mainland countries for a given income level.

47. Again, income growth is found to be the key factor explaining improvements in gross primary school enrollment, with an elasticity of 0.32 . However, we find no significant correlation between school enrollment and civil conflict or freedom indicators. Macroeconomic policies do not have an impact on primary school enrollment, with the exception that a positive (though modest) relationship is found between openness to foreign trade and gross primary school enrollment. We also find a positive relationship between inflation and gross primarily school enrollment; this may reflect the impact of high fiscal spending on education and the resultant impact of higher domestic financing on inflation. As above, landlocked countries do not significantly differ in school enrollment from countries with access to the sea, while island countries exhibit higher enrollment rates than nonisland countries for each income level.

\section{Expanded model-with quality of growth variables, HIV/AIDs and latitude}

48. We now add three quality of growth variables to the expanded model which have been associated in previous studies with an increase in income and/or a decrease in poverty, including income inequality (the gini coefficient), public healthcare expenditure as a share of GDP, and the share of the population with access to safe water. Given the lack of time series data, we use the latest observation for each country: the gini coefficient reflects the latest data available, healthcare reflects 1997 (or the latest estimate of) public health care expenditure as a share of GDP, and access to safe water reflects 1997 (or latest) estimates. In addition, we include HIV/AIDs prevalence rates as an additional control variable, as well as latitude (the 
distance in degrees of the capital city from the equator) as a proxy for geography/tropical effects. The empirical results are summarized in Table 8 below.

49. With respect to life expectancy (LE), we find that a 10 percent increase in income leads to a 0.8 percent increase in LE, inline with the basic model. While macroeconomic policy variables do not significantly affect $\mathrm{LE}$, we find that quality of growth matters: improved income distribution (lower gini coefficient) and higher public healthcare expenditure increase live expectancy. We also find that civil conflict reduces LE, while institutional and civil freedoms increase LE, as we assumed. Island countries are found to be associated with higher LE for a given level of income, though landlocked countries do not have significantly different LE than those with access to the sea. In addition, countries with higher HIV/AIDs prevalence rates exhibit lower LE for a given income level. Finally, we find a country's latitude does not significantly affect LE. The model explains 55 percent of the change in LE.

50. For infant mortality rates, we find that a 10 percent increase in income leads to a $2 \frac{1}{2}$ percent decline in infant mortality rates (compared with 3-4 percent in the basic model). In terms of macro policy variables, we find that lower inflation and higher government expenditure reduce IMRs, while increased openness to trade has a marginally negative impact on IMRs. In terms of quality of growth, we find that lower income inequality, and higher public health care expenditure and access to safe water all lead to lower IMRs. For the control variables, we find that the lack of civil conflict and higher institutional and individual freedom reduces IMR for a given level of income, while island countries exhibit lower IMRs for a given income level. Neither HIV/AIDs prevalence rates nor latitude are found to directly affect IMRs. It is not clear why increased openness to trade would have a negative, albeit small, impact on IMRs, and this will need to be studied further. The model explains 76 percent of the change in infant mortality rates over the period studied.

51. With respect to gross primary school enrollment, a 10 percent increase in income is found to increased primary school enrollment by $3 \frac{1}{2}$ percent, similar to the basic model. In terms of macro variables, we find that increased openness to trade and inflation increase enrollment for a given income level. In terms of quality of growth, the model suggests that higher inequality and higher public healthcare expenditure lead to higher school enrollment rates. While HIV/AIDs prevalence rates and landlocked countries are not found to be significant explanatory variables, island countries and countries further from the equator exhibit higher school enrollment rates for a given income level. We find somewhat surprisingly that lower freedom and higher inequality would increase enrollment rates and will need to study these results further as well as test for robustness as the model explains only 42 percent of the change in gross primary school enrollment. 
Table 8. Summary of Expanded Model, Including Quality of Growth 1/

\begin{tabular}{|c|c|c|c|}
\hline & $\begin{array}{l}\ln \text { (life } \\
\text { expectency) }\end{array}$ & $\begin{array}{l}\text { Ln (infant } \\
\text { mortality } \\
\text { rate) }\end{array}$ & $\begin{array}{l}\text { In (primary } \\
\text { school } \\
\text { enrollment) }\end{array}$ \\
\hline \multicolumn{4}{|l|}{ Basic model } \\
\hline In (per capita GDP) & $0.08 *$ & $-0.247 *$ & $0.36 *$ \\
\hline Time trend & & & $-0.041 *$ \\
\hline \multicolumn{4}{|l|}{ Macro-related policy variables } \\
\hline Openess to trade (exports+imports/GDP) & & $0.002 *$ & $0.002 *$ \\
\hline Inflation rate $(1+$ inflation $)$ & & $0.27 *$ & $0.854 *$ \\
\hline \multicolumn{4}{|l|}{ Terms of trade $(1995=100)$} \\
\hline Government expenditure/GDP & & $-0.003 *$ & \\
\hline \multicolumn{4}{|l|}{ Quality of growth variables } \\
\hline Inequality (gini coefficient) & $-0.003 *$ & $0.008 *$ & $0.009 *$ \\
\hline Public health care expenditure/GDP 3/ & $0.056 *$ & $-0.15 *$ & $0.104 *$ \\
\hline Access to safe water & & $-0.18 *$ & \\
\hline \multicolumn{4}{|l|}{ Control variables $2 /$} \\
\hline Civil conflict & $-0.11 *$ & $0.17 *$ & $4 /$ \\
\hline Freedom index & $-0.006 *$ & $0.016 *$ & $0.018 *$ \\
\hline \multicolumn{4}{|l|}{ Landlocked countries } \\
\hline Island countries & $0.11 *$ & $-0.72 *$ & $0.36 *$ \\
\hline IHIV/AIDs prevalence rate & $-0.016 *$ & & \\
\hline Latitude & & & $-0.01 *$ \\
\hline Adjusted R-squared & 0.55 & 0.76 & 0.42 \\
\hline Total panel (unbalanced) observations & 145 & 136 & 128 \\
\hline Observations per cross section (country) & 5 & 5 & 5 \\
\hline Number of cross sections (countries) used & 29 & 29 & 29 \\
\hline
\end{tabular}

Note: * denotes significance at the 1 percent level,

** denotes significance at the 5 percent level, and

*** denotes significance at the 10 percent level.

1/ This table reports the results of adding the indicated control variables to the instrumental variable estimator (lagged income was used to instrument income) using generlized least squares method. 2/ See Appendix for definition of control variables.

3/ Includes scalar variable of public health care expenditurc/GDP ratio in 1997 (or latest estimate), based on World Bank, World Development Indicators. Time series data not available for the 1970s-1980s.

4/ Individually significant with income variable, but not significant in model form. 


\section{Tentative Conclusions}

52. The study finds that economic growth has been an important factor leading to nonincome poverty reduction in Africa through both an historical review of developments over the previous three decades, as well as through empirical analysis. The empirical results suggest that strong and sustainable growth in SSA will lcad to similarly strong and sustainable declines in nonincome poverty (life expectancy, infant mortality rates, and primary school enrollment). Equally important, there is no evidence that the adoption of a structural adjustment program increases poverty. We also find that while economic growth is important to reduce nonincome poverty, other factors are also significant.

53. We find that lower income inequality and the provision of basic social services (public health care and access to safe water) are significant factors that lead to lower poverty levels for a given income level. We also find-not surprisingly-that countries in civil conflict exhibit higher rates of poverty than nonconflict countries, and that, when we exclude the conflict countries, poverty trends in sub-Saharan Africa are much improved. One conclusion drawn is that rapid improvements in poverty in Africa require the early resolution of conflicts and strong post-conflict economic recovery programs, as a large share of SSA has experienced some degree of civil conflict in the past 25 years. In addition, we find higher levels of civil and institutional freedom to be associated with lower infant mortality rates and higher life expectancy, suggesting the benefits of such freedoms go beyond economic growth, directly to improving human development. As important, we find that the recent surge in HIV/AIDs prevalence rates in southern and east Africa is an important factor explaining the lack of improvement in life expectancy in recent years. We also find that island economies exhibit lower levels of poverty for a given income level than mainland economies, while there is no significant difference between landlocked countries and countries with access to the sea. Finally we find that latitude has no significant direct influence on life expectancy or infant mortality rates, while it does seem to matter for primary school enrollment rates.

54. While these results are preliminary, the consistency of the basic results - that economic growth is important for sustained poverty reduction in Africa-across empirical model formulations is encouraging. Nonetheless, the empirical model could usefully be expanded, in terms of building a system of equations, which allow explicitly for feedback between income and human development. We would also hope that these relationships could be tested more systematically based on household level survey data. In this regard, the current focus on the collection of household level poverty data is encouraging. though more needs to be done in this area, particularly with respect to the quality of the survey data and consistency across surveys and countries. Finally, there is a need to better bridge the gap between research being carried out on factors influencing health and education in Africa, at the micro (household) level, and the income and growth research that is being carried out using macro-level data. 


\section{References}

Aghion, Philippe, Eve Caroli, and Cecilia García-Peñalosa (December 1999), "Inequality and Economic Growth: The Perspective of the New Growth Theories," Journal of Economic Literature, Vol. 37, 1615-1660.

Ali, A.A.G. (2001), "Poverty: Dimensions and Prospects," Unpublished manuscript, Arab Planning Institute, Kuwait.

Ali, A.A.G. and I. Elbadawi (2001), "Growth Could be Good for the Poor," Unpublished manuscript, Arab Planning Institute, Kuwait.

Banerjee, Abhijit V. and Esther Duflo (1999), "Inequality and Growth: What Can the Data Say?" Manuscript, MIT.

Barro, Robert J. and Jong-Wha Lee (September 2000), "International Data on Educational Attainment Updates and Implications," National Bureau of Economic Research, Working Paper Series, 7911:1-36.

Barro, Robert J. (March 2000), "Inequality and Growth in a Panel of Countries," Journal of Economic Growth, 5, No. 1:5-32.

Barro, Robert J., 1999, "Inequality, Growth, and Investment," National Bureau of Economic Research (NBER), Cambridge, MA, Working Paper, No. 7038:1-52.

Barro, Robert J. (1999), "Human Capital and Growth in Cross-Country Regressions," Swedish Economic Policy Review 6, 237-277.

Bidani, Benu and Martin Ravallion (1997), "Decomposing Social Indicators Using Distributional Data," Journal of Econometrics, 77:125-139.

Bruno, Michael, Martin Ravallion, and Lyn Squire (1996), "Equity and Growth in Developing Countries: Old and New Perspectives on the Policy Issues," World Bank, Policy Research Working Paper 1563.

Bruno, M., Ravallion, M., and Squire, L. (1995), "Equity and Growth in Developing Countries: Old and New Perspectives on the Policy Issues," Paper presented at International Monetary Fund Conference on Income Distribution and Sustainable Growth, Washington, DC, June 1-2.

Case, Anne (2000), "Health, Income and Economic Development," Unpublished manuscript prepared for the ABCDE Conference, World Bank, May 1-2 2000.

Chen, Shaohua and Martin Ravallion, 2000, "How did the World's Poorest Fare in the 1990s?" World Bank Policy Research Working Paper, No. 2409 (Washington: World Bank). 
Chauduri, S. and Martin Ravallion (1994), "How Well do Static Welfare Indicators Identify the Chronically Poor?" Journal of Public Economics, 53-3:367-394.

Deaton, Angus (1999), "Inequalities in Income and Inequalities in Health," National Bureau of Economic Research (NBER), Cambridge, MA, Working Paper, No. 7141:1-37.

Deaton, Angus (2001), "Relative Deprivation, Inequality, and Mortality," National Bureau of Economic Research (NBER), Cambridge, MA, Working Paper, No. 8099:1-33.

Deininger, Klaus and Lyn Squire (1996), "A New Data Set Measuring Income Inequality." The World Bank Economic Review, 10(3):565-591.

Demery, Lionel, and Lyn Squire (1996), "Macroeconomic Adjustment and Poverty in Africa: An Emerging Picture." World Bank Research Observer 11-1:39-59.

Dollar, David, and Aart Kraay, 2000, "Growth Is Good for the Poor," World Development Research Group (Washington: World Bank).

Duffy, John, and Chris Papageorgiou (2000), "A Cross-Country Empirical Investigation of the Aggregate Production Function Specification," Journal of Economic Growth, (March) 5, $87-120$.

Easterly, William and Ross Levine (1996), "Africa's Growth Tragedy: Policies and Ethic Divisions," Harvard Institute for International Development, Development Discussion Paper 536.

Fielding, D. (2001), "Why is Africa so Poor? A Structural Model of Growth and Income," CSAE Working Paper WPS/2001-5, University of Oxford.

Fields, G. S. (1989), "Changes in Poverty And Inequality in Developing Countries," World Bank Research Observer, 4.

Frankel, Jeffrey A. and David Romer (1999), "Does Trade Cause Growth?" The American Economic Review, (June) 379-399.

Michael Funke and Holger Stulik (2000), "On Endogenous Growth with Physical Capital, Human Capital and Product Variety," European Economic Review, 44:491-515.

Galor, Oded and Omer Moav (2000), "From Physical to Human Capital Accumulation: Inequality in the Process of Development," Maurice Falk Institute for Economic Research in Israel. Discussion Paper (July) No. 00.11:1-[32].

Ghura, Dhaneshwar and Michael T. Hadjmichael (1996), "Growth in Sub-Saharan Africa," Staff Papers, International Monetary Fund, Vol. 43 (September), pp. 605-34. 
Haacker, Markus (2001), "The Economic Consequences of HIV/AIDs in Southern Africa," Discussion paper presented at IMF Workshop on Macroeconomic Policies and Poverty in Africa, April.

Lipton, Michael, and Martin Ravallion (1995), "Poverty and Policy," in Jere Behrman and T.N. Srinivasan, eds, Handbook of Development Economics, Volume III, Amsterdam: Elsevier Science.

Moser, Gary, Nicholas Staines, and Lars Engstom (2001), "Economic Development in PostConflict Countries in Sub-Saharan Africa," IMF working paper (forthcoming).

Perotti, Roberto (1996), "Growth, Income Distribution, and Democracry: What the Data Say," Journal of Economic Growth, Vol. 1, (June), pp. 149-187.

Ranis, Gustav, Frances Stewart, and Alejandro Ramirez, 2000, "Economic Growth and Human Development," World Development, Vol. 28, (February), pp. 197-219.

Ravallion, M. and Datt, G. (1991), "Growth And Redistribution Components of Changes in Poverty Measure: A Decomposition with Applications to Brazil and India in the 1980s," LSMS Working Papers \#83, Washington, DC: World Bank.

Ravallion, Martin and Shaohua Chen, 1997, "What Can New Survey Data Tell Us About Recent Changes in Distribution and Poverty?" World Bank Economic Review, Vol. 11(2):357-82.

Roemer, Michael and Mary Kay Gugerty, 1997, "Does Economic Growth Reduce Poverty?" CAER Discussion Paper No. 4 (Cambridge MA: Consulting Assistance on Economic Reform II Project).

Sen, Amartya (1976), "Poverty: An Ordinal Approach to Measurement," Econometrica 442:219-232.

Squire, Lyn (1993), "Fighting Poverty," American Economic Review, 83-2:377-382.

Wilkinson, Richard G. (1996), "Unhealthy Societies: The Afflictions of Inequality," London, Routledge. 


\title{
Appendix: Data Definitions and Sources 1/
}

\author{
Variable Definition \\ INF Infant mortality rate (number of deaths per 1,000 live birth). Source: World Bank, World Development \\ Indicators; $48 \mathrm{SS} \Lambda$ countries. \\ LIFE Life expectancy at birth (years). Source: World Bank, World Development Indicators; 48 SSA countries. \\ PEDU Gross primary school enrollment rates (gross percent). Source: World Bank, World Development Indicators. (For \\ this variable only, time dimension is different owing to data availability $(1970,1975,1980,1985,1990$, and \\ 1995).] ; 46 SSA countries. \\ PIMF Real GDP per capita in international dollars (using purchasing power parity). Source: IMF, World Economic \\ Outlook; 46 SSA countries. \\ CPI Previous fivc-ycar period's average annual inflation rate calculated from consumer price index (percent). Source: \\ IMF, World Economic Outlook; 46 SSA countries. \\ GINI Latest estimate of gini coefficient for each country, as compiled by Dollar and Kraay, and updated by the most \\ recent World Bank, World Development Indicators; 29 SSA countries. (Scalar variable.) \\ GOV General government consumption (as a percent of GDP). Source: World Bank, World Development Indicators; \\ 48 SSA countries. \\ HEALTH 1997 or latest estimate of public healthcare expenditure as a share of GDP. Source: World Bank, World \\ Development Indicators; 44 SSA countries. (Scalar variable.) \\ HIV/AIDs $\quad$ HIV/AIDs prevalence rates in adult population. Source: World Bank, World Development Indicators; 44 SSA \\ countries. (Scalar variable.) \\ INFLATION $\ln (1+\mathrm{CPI})$. \\ LAT Number of degrees in latitude above or below the equator. (Scalar variable.) Source: CIA 2000 World Fact Book. \\ TOT Terms of trade, goods and services (index, 1995=100). Source: IMF, World Economic Outlook; 46 SSA \\ countries. \\ TRA Openness measure: (export + import)/GDP (percent of GDP). Source: World Bank, World Development \\ Indicators; 48 SSA countries. \\ LOC $\quad(1,1,1,1,1,1)$ for landlocked countries and $(0,0,0,0,0,0)$ otherwise (except for Ethiopia, which changes to \\ landlocked in 1997); 48 SSA countries. (Scalar variable.) \\ ILND $\quad(1,1,1,1,1,1)$ for island countries and $(0,0,0,0,0,0)$ otherwise; 48 SSA countries. Island countries comprise Cape \\ Verde, Comoros, Madagascar, Mauritius, Sao Tome and Principe, Seychelles and Equatorial Guinea (given the \\ significant role of Bioko). (Scalar variable.)
}




\section{Appendix (continued): Data Definitions and Sources 1/}

\begin{tabular}{ll}
\hline Variable & \multicolumn{1}{c}{ Definition } \\
\hline WAR & $\begin{array}{l}\text { Dummy for armed conflict: } 1 \text { if there is in at least one year of war or substantial conflict during previous } 5 \text { year } \\
\text { period, 0 otherwise. Source: World Military and Social Expenditure, 1996; 48 SSA countries }\end{array}$ \\
WATER & $\begin{array}{l}\text { 1997 estimate of the percentage of population which has access to safe water, defined in terms of three groups } \\
\text { (low, medium or high access). Source: World Bank, World Development Indicators; } 47 \text { SSA countries. (Scalar } \\
\text { variable.) }\end{array}$ \\
& $\begin{array}{l}\text { Scale from 2-14 for civil and institutional freedom, with } 2 \text { the most free. Sum of indices of political rights and } \\
\text { civil liberties obtained from Freedom House (New York). Each rating of countries is on a seven-point (1-7) scale } \\
\text { for levels of political rights and civil liberties, with 1 the most free. Source: Freedom House; } 48 \text { SSA countries. }\end{array}$ \\
& (1,2,3,4,5,6) for all countries; trend variable.
\end{tabular}

1/ All the variables are in panel form: time dimension $T=6$ periods $(1972,1977,1982,1987,1992$, and 1997), and $N($ maximum $)=48$ sub-Saharan African countries. 
Appendix (Continued): Country Groupings Used in Table 6

\begin{tabular}{|c|c|c|c|c|c|c|c|c|c|c|}
\hline $\begin{array}{l}\text { Country } \\
\text { Code }\end{array}$ & $\begin{array}{l}\text { Country } \\
\text { Name }\end{array}$ & $\begin{array}{l}\text { Alt } \\
\text { Countrics }\end{array}$ & $\begin{array}{l}\text { High } \\
\text { Income }\end{array}$ & $\begin{array}{l}\text { Low } \\
\text { Income }\end{array}$ & $\begin{array}{l}\text { Fast } \\
\text { Growth }\end{array}$ & $\begin{array}{l}\text { Slow } \\
\text { Growth }\end{array}$ & $\begin{array}{l}\text { Civil } \\
\text { Conflict }\end{array}$ & $\begin{array}{l}\text { No } \\
\text { Civil } \\
\text { Contlict } \\
\end{array}$ & Adjusters & $\begin{array}{l}\text { Non- } \\
\text { Adjusters }\end{array}$ \\
\hline$\Lambda G O$ & ANGOLA & $\mathrm{AGO}$ & AGO & BDl & BFA & AGO & AGO & _BEN & _BEN & AGO \\
\hline BEN & BENIN & BWA & BWA & - BEN & BWA & BDI & BDI & BFA & BFA & BDI \\
\hline BWA & BOTSWANA & BEN & CIV & BFA & $\mathrm{CMR}$ & BEN & $\mathrm{COD}$ & BWA & CIV & CAF \\
\hline $\mathrm{BFA}$ & BURKINA FASO & $\mathrm{CMR}$ & CMR & $\mathrm{CAF}$ & $\mathrm{COG}$ & $\mathrm{CAF}$ & ETH & CAF & ETH & CMR \\
\hline BDI & BURUNDI & TCD & COD & ETH & ETH & CIV & GNB & CIV & GIIA & COD \\
\hline $\mathrm{CMK}$ & CAMEKOON & BFA & $\operatorname{COG}$ & GNB & GAB & COD & LBR & CMR & GIN & COG \\
\hline$-\mathrm{CPV}$ & CAPE VERDE & CAF & COM & KEN & GIN & _COM & $\mathrm{MOZ}$ & ${ }_{-} \mathrm{COG}$ & KEN & COM \\
\hline $\mathrm{CAF}$ & CENTRAL AFRICAN REP. & $\mathrm{CPV}$ & $\mathrm{CPV}$ & LSO & GMB & $\mathrm{CPV}$ & NGA & $\mathrm{COM}$ & LLSO & CPV \\
\hline TCD & CHAD & $\mathrm{BDI}$ & DJI & MDG & GNB & DJI & RWA & CPV & MLI & DJJ \\
\hline $\mathrm{COM}$ & COMOROS & $\mathrm{COM}$ & GAB & $-\mathrm{MLI}$ & _GNQ & GIIA & ${ }_{-} \mathrm{SDN}$ & DJI & _MWI & _GAB \\
\hline $\mathrm{COD}$ & CONGO, DEM. REP. OF & $\mathrm{COG}$ & GH $\Lambda$ & MOZ & KEN & LBR & SLE & $\mathrm{GAB}$ & NER & GMB \\
\hline $\mathrm{COG}$ & CONGO, REPUBLIC OF & DJ! & _GIN & _MWl & _LSO & _MDG & $-T C D$ & GHA & SEN & GNB \\
\hline $\mathrm{CIV}$ & COTE D IVOIRE & GNQ & GMB & NER & _.MOZ & _MLI & _UGA & GIN & ${ }_{-}^{-} \mathrm{TGO}$ & GNQ \\
\hline $\mathrm{DJI}$ & DJIBOUTI & CIV & GNQ & NGA & MRT & NAM & & GMB & -TZA & - \\
\hline GNQ & EQUATORIAL GUNNEA & _COD & LBR & RWA & MUS & NER & & GNQ & _UGA & MDG \\
\hline ERI & ERITRIA & ERI & MRT & SDN & MWI & ${ }_{-} \mathrm{NGA}$ & & KEN & ZWE & MOZ. \\
\hline ETH & ETHIOPIA & ETH & MUS & SLE & ${ }_{-} \mathrm{SDN}$ & -RWA & & _LSO & & _MUS \\
\hline $\mathrm{GAB}$ & GABON & GAB & NAM & STP & SWZ & SEN & & ${ }_{-} \mathrm{MDG}$ & & NGA \\
\hline GMB & GAMBIA, THE & _GHA & SEN & - TCD & SYC & SLE & & MLl & & RWA \\
\hline GHA & GHANA & _GIN & _SWZ & -TZA & TCD & STP & & - MRT & & SDN \\
\hline GN & GUTNEA & GNB & SYC & _UGA & $-T Z A$ & $\mathrm{TGO}$ & & _MUS & & _SLE \\
\hline GNB & GUINEA-BISSAU & GMB & TGO & ZMB & _UGA & ZMBB & & MWI & & $-\mathrm{TCD}$ \\
\hline KEN & KENYA & KEEN & $\mathrm{ZAF}$ & & ZAF & ZZWE & & _NAM & & ZZMB \\
\hline LSO & LESOTHO & LSO & ZWE & & & & & _NER & & \\
\hline LBR & LIBERIA & MDG & & & & & & SEN & & \\
\hline $\mathrm{MDG}$ & MADAGASCAR & L.BR & & & & & & Slle & & \\
\hline MWI & MALAWJ & MRT & & & & & & SWW & & \\
\hline MLI & MALI & MWI & & & & & & SYC & & \\
\hline MRT & MAURITANIA & $\mathrm{MOZ}$ & & & & & & - TGO & & \\
\hline MUS & MAURITIUS & MUS & & & & & & -TZA & & \\
\hline $\mathrm{MOZ}$ & MOZAMBIQUE & MLI & & & & & & ZAF & & \\
\hline NAM & NAMIBIA & NAM & & & & & & ZZMB & & \\
\hline NER & NIGER & NER & & & & & & ZWWE & & \\
\hline $\mathrm{NGA}$ & NIGERIA & NGA & & & & & & & & \\
\hline KWA & RWANDA & _RWA & & & & & & & & \\
\hline STP & SAO TOME \& PRINCIPE & STP & & & & & & & & \\
\hline SEN & SENEGAL & SEN & & & & & & & & \\
\hline SYC & SEYCHELLES & _SYC & & & & & & & & \\
\hline SLE & SIERRA LEONE & _LE & & & & & & & & \\
\hline SOM & SOMALIA & SOM & & & & & & & & \\
\hline ZAF & SOUTH AFRICA & ZAF & & & & & & & & \\
\hline SDN & SUDAN & $\mathrm{SDN}$ & & & & & & & & \\
\hline SW7. & SWAZILAND & _Swz & & & & & & & & \\
\hline TZA & TANZANIA & _TZA & & & & & & & & \\
\hline TGO & TOGO & _TGO & & & & & & & & \\
\hline _UGA & UGANDA & _UGA & & & & & & & & \\
\hline Z $\mathrm{ZMB}$ & ZAMBIA & $\mathrm{ZMB}$ & & & & & & & & \\
\hline ZWE & ZIMBABWE & $Z W E$ & & & & & & & & \\
\hline
\end{tabular}

